\title{
ERUPCIÓN DEL VOLCÁN DE SAN SALVADOR EL 7 DE JUNIO DE $1917^{1}$
}

\author{
LeROY W. McConneLL \\ Misionero de Central American Mission \\ San Salvador, 15 de junio de 1917
}

Todavía nos encontramos en gran confusión, como resultado del gran terremoto, sin poder poner nuestras manos en lo que queremos cuando lo queremos; por lo que me disculparán amablemente que utilice mi lápiz en esta ocasión.

Aunque los periódicos de Estados Unidos están muy ocupados por las grandes demandas de la guerra, etc., supongo que al menos mencionaron la erupción y el terremoto sufridos aquí. Estoy escribiendo esta breve descripción, pensando que llegaría al Boletín e informaría a muchos que están interesados en conocer algunos detalles.

El jueves 7, a las 6:30 P. M., se sintió el primer terremoto, que fue lo suficientemente fuerte como para hacernos levantar y agarrarnos a los postes de la puerta, mientras una multitud salía corriendo a la calle. La mayoría volvió a entrar a sus casas y nos sentamos a cenar, comentando en broma lo ocurrido, aunque notando que la tierra seguía temblando ligeramente. Pronto llegó un terremoto más fuerte que envió a todos a la calle, donde nos quedamos el resto de la noche. El último terremoto había causado algunos daños, pero pronto le siguieron otros más fuertes, que podían oírse venir como una gran tormenta, que casi lo tumbaban a uno, acompañado por el sonido de la caída de muebles, paredes y casas enteras. En la esquina, cerca de dos casas abajo de la de nosotros, una de las casas más grandes y finas de la ciudad, con gruesos muros de ladrillo, se vino abajo completamente, con gran ruido, enterrando por completo todos los muebles, etc.

Durante varias horas, o hasta las 11:00 de la noche, esta situación continuó: el suelo temblando -como gelatina- continuamente, por los fuertes terremotos ondulatorios que venían de vez en cuando. Hubo terremotos el resto de la noche, pero menores y a intervalos más largos.

$\mathrm{Al}$ principio la gente se puso a gritar y repetían en voz alta sus oraciones mecánicas cada vez que un temblor fuerte venía, pero luego se calmaron algunos. La planta de energía se apagó con el segundo terremoto, dejando todo en oscuridad, aunque la luna ayudaba a pesar de que tenía que brillar a través de un manto de nubes que suavemente dejaba caer su lluvia.

1 Esta crónica fue publicada originalmente en The Central American Bulletin, Vol. XXIII, n. ${ }^{\circ}$ III del 15 de julio de 1917. La traducción fue realizada por Andrea María Constanza Castillo, estudiante de $5 .^{\circ}$ año de la Licenciatura en Economía y Negocios, ESEN. 
Temprano, un incendio estalló en una de las farmacias más grandes de la ciudad, que se quemó hasta el suelo, llevándose con ella otra de las tiendas más grandes de la ciudad.

Entre los terremotos, nos apresuramos a conseguir sombrillas e impermeables, que nos arreglamos para encontrar después de escalar sobre muebles destruidos, etc. El guardarropa estaba boca abajo, y usted puede imaginar el golpe que la máquina de escribir debió de haber recibido, que estaba inicialmente encima del guardarropa.

El resto de la noche pasamos en el suelo bajo los paraguas y notamos que algo estaba cayendo, que al principio pensamos eran cenizas del fuego. Entonces creímos el rumor de que el volcán de San Salvador, a espaldas nuestras, había estallado. A la luz del día encontramos los paraguas y ropa no solo cubiertos por la arena, sino también con una mancha como quemada cuando la limpiábamos. Los componentes sulfúricos en el material, mezclados con el aire húmedo, habían dado como resultado ácido sulfúrico, que también destruyó la vegetación.

Pronto se confirmó que la montaña, al pie de la cual se encuentra esta ciudad, había entrado en erupción, pero - para fortuna de nosotrosal otro lado de ella. Una gran corriente de lava continúa fluyendo y cruzó la línea del ferrocarril en el valle abajo, por lo que no hay trenes.

A la mañana siguiente, todos regresaron cautelosamente a investigar sus hogares, y probablemente no hay casa que no esté muy dañada, mientras que un gran porcentaje está completamente en el suelo. La pared entre nosotros y nuestros vecinos de al lado está completamente abajo, y otras tres o cuatro paredes están parcialmente caídas. Las tejas del techo se movieron, dejando entrar mucha agua, pero fue de las primeras cosas que arreglamos con la ayuda de algunos creyentes de otra ciudad, aunque todavía gotea mucho.
Por tres noches todo el mundo durmió en las calles, a medida que los terremotos continuaron, aunque modificados en forma. Una gran parte de la gente sigue durmiendo en calles, parques, lotes baldíos, etc., en los más crudos refugios que cada cual ha armado para sí mismos y donde la lluvia los moja bien.

La falta de agua durante tres días se añadió a los problemas, pero el Gobierno proclamó ley marcial y ha manejado las cosas de manera más enérgica y loable.

Miles de personas salieron de la ciudad hacia el oriente, donde no hubo daños, pero se piensa que regresarán gradualmente, ya que la generosa ayuda de otras partes se está concentrando aquí.

El terremoto continúa cada día y noche, y hemos tenido dos desde que empecé esta carta, pero han sido suaves, por lo que el sueño es interrumpido por la noche.

Como la advertencia fue dada, nadie murió aquí, por lo que los creyentes están sanos y bien, aunque algunos sin refugio. Los creyentes de Ostuma enviaron en caballos cuatro cargas de comida y ayuda para distribuir, por lo que tampoco hay hambre.

Tenemos mucho por lo que alabar al Señor, especialmente por la vida, la salud, el refugio, $y$ que casi ninguna de nuestras pertenencias fue dañada totalmente.

Esto es oportuno para impulsar la evangelización y tenemos la intención de hacerlo tan pronto como sea posible. 